\title{
Traffic seismicity loaded historical building frequency parameters identification due to most commonly used truck in Slovakia
}

\author{
Daniel Papán ${ }^{1, *}$, and Veronika Valašková ${ }^{1}$ \\ ${ }^{1}$ Department of Structural Mechanics and Applied Mathematic, Faculty of Civil Engineering, \\ University of Žilina, Univerzitná 8215/1, 01026 Žilina, Slovak Republic
}

\begin{abstract}
Experimental investigation and combination with numerical modelling is one of the progressive method in many scientific areas. The structural dynamics including traffic seismicity effects are also becoming an increasing topic. The aim of this paper was to realize the numerical analysis of heritage Upper Gate in Modra - Slovakia and FEM simulation of the lorry T-815 natural vibration. These subsystems are dominant processes in traffic seismicity vibration effects in buildings. For this purpose the variants of FE model by computing program Scia engineering has been created for building and software ADINA for lorry. These models are important for the assessment of the dynamic vibration transmissibility due to mechanical impact load properties. The results of this simulation was evaluated in frequency area. Next part of the investigation was the realisation of the experimental measurement. The results obtained from the experiment were compared with FE analysis. Using of the theoretical analysis, experimental procedures results and FEM simulation of the natural vibration it seem to be the practical application for engineering practice in prediction and assessment buildings vibration due to seismicity induced by traffic.
\end{abstract}

\section{Introduction}

The roads and the transport structures are subjected to direct dynamic effects of moving load. Unevenness in the pavement is the main source of kinematic excitation of the vehicle. It significantly effects the size of the contact forces between the pavement and vehicle. This is the reason to deal with it. The dimension of road unevenness is the higher order then pavement deflection or tire unevenness. So it is fully reasonable to take into account the unevenness located on the road only as a source of kinematical excitation of vehicle. The real load acting on the roads is variable in time and in frequency composition. This should be known for the solution of many engineering tasks as lifetime, design, reliability, structure development, micro tremor, etc.

The reliable building structures design in seismically active regions needs a detailed analysis of SI (Soils-structure interaction) under technical seismicity load. Nowadays

* Corresponding author: daniel.papapn@,fstav.uniza.sk 
technical seismicity is part of the environmental issues. The increase in vibration induced by different traffic has an unfavourable impact on building constructions and the people living there. The objects placed near the road and railway communications are highly influenced by vibrations due to technical seismicity. The comprehensive theoretical and experimental analysis of the dynamic response of the structure must be solved as a part of the task.

\section{Representative vehicle fem frequency analysis}

One of the most important part of the process of numerical simulation is to create a proper computing model. For this case the quarter model of TATRA 815 lorry was chosen as the most representative vehicle (Fig.1). The theoretical solution is based on the FEM. FEM has been mostly used since computers calculation started as one of the possible way to find solution on systems of differential equations. In this case the vehicle moved on the pavement and overcome obstacle belongs among non-stationary dynamic actions. These actions are described by the following differential equation:

$$
[\boldsymbol{M}] \cdot\{\ddot{\boldsymbol{u}}(t)\}+[\boldsymbol{C}] \cdot\{\dot{\boldsymbol{u}}(t)\}+[\boldsymbol{K}] \cdot\{\boldsymbol{u}(t)\}=\{\boldsymbol{F}(t)\}
$$

Where $[\boldsymbol{M}],[\boldsymbol{C}]$ and $[\boldsymbol{K}]$ are mass, damping and stiffness matrices.
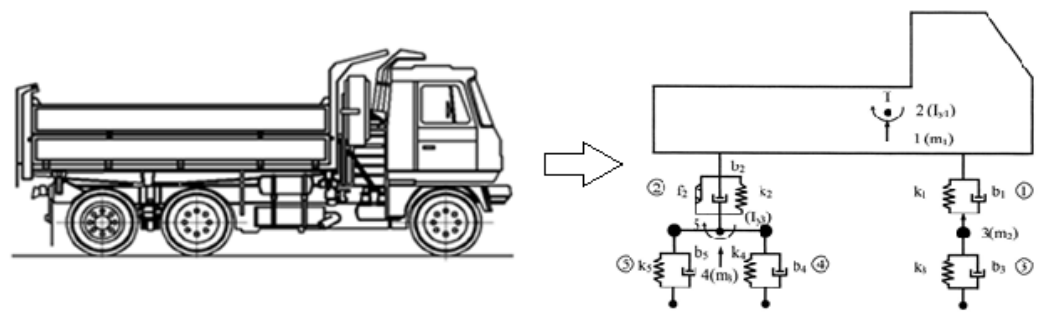

Fig. 1. Half-part model of lorry T-815.

Important part of simulation is to choose the appropriate model of vehicle. Model has to be represented with appropriate mathematical formulation. Half-part model are usually preferred and used for 2D analysis as a combination of mass, spring and beam elements. This discrete model of the vehicle with finite degrees of freedom makes solution easier from the mathematical point of view. This assumption changes partial differential equations to the ordinary differential equations $[2,3]$.

The main characteristic of the half part model is defined by three diagonal matrices. They are the mass $\{\mathbf{m}\}$, stiffness $\left\{\mathbf{k}_{\mathbf{i}}\right\}$ and damping $\left\{\mathbf{b}_{\mathbf{i}}\right\}$ matrices which contain experimentally measured values [3].

$$
\begin{aligned}
& \left\{\mathbf{m}_{\mathbf{i}}\right\}_{\mathbf{D}}=\left\{m_{1}, I_{\mathrm{y} 1}, m_{2}, m_{3}, I_{\mathrm{y} 3}\right\}_{\mathrm{D}}=\{11475 ; 31149 ; 455 ; 1070 ; 466\}_{\mathrm{D}} \quad\left[\mathrm{kg}, \mathrm{kg} \cdot \mathrm{m}^{2}\right] \\
& \left\{\mathbf{k}_{\mathbf{i}}\right\}_{\mathbf{D}}=\left\{k_{1}, k_{2}, k_{3}, k_{4}, k_{5}\right\}_{\mathrm{D}}=\{143716.5 ; 761256 ; 1275300 ; 2511360 ; 2511360\}_{\mathrm{D}} \quad[\mathrm{N} / \mathrm{m}] \\
& \left\{\mathbf{b}_{\mathbf{i}}\right\}_{\mathbf{D}}=\left\{b_{1}, b_{2}, b_{3}, b_{4}, b_{5}\right\}_{\mathrm{D}}=\{19228,260197,2746,5494,5494\}_{\mathrm{D}}[\mathrm{kg} / \mathrm{s}]
\end{aligned}
$$

Determined as a result of the calculating natural frequencies.

$$
\{\mathbf{f}\}=\left\{f_{(1)} ; f_{(2)} ; f_{(3)} ; f_{(4)} ; f_{(5)}\right\}=\{1.13 ; 1.45 ; 8.89 ; 10.91 ; 11.71\}
$$




\section{The affecting monumental building fem frequency analysis}

These case study presents the frequency domain analysis of one monumental building in the area Modra - Slovakia. For the purpose of the case study was chosen Upper Gate (Fig.2). built in $1610-1646$. The Upper Gate is located near the roadway line that produced dynamic load due to technical seismicity. The house of this type was selected as the most frequent building located near the roadway line of 2nd class (no. 502, Bratislava Smolenice) in the town center in Modra, Slovakia [1].

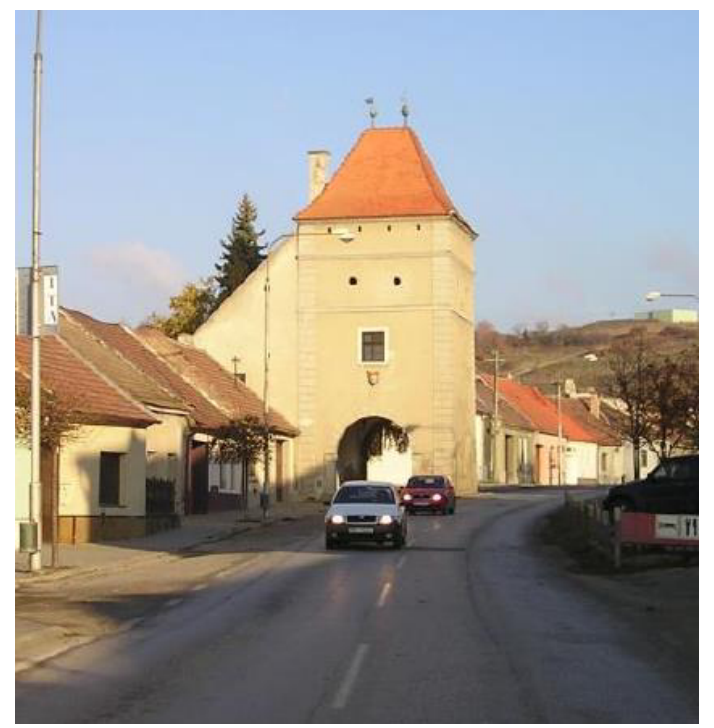

Fig. 2. The view on the historical Upper Gate building.

The analysis of SI applied in Modra locality types of FEM model were created in Scia engineering software. This computing models was used with dynamic parameters evaluation in frequency domain. For the vibration dominant frequency bands and the vibration transfer 3D FEM model was used. Natural frequency values and modes of vibration were calculated for this computing model type [4].
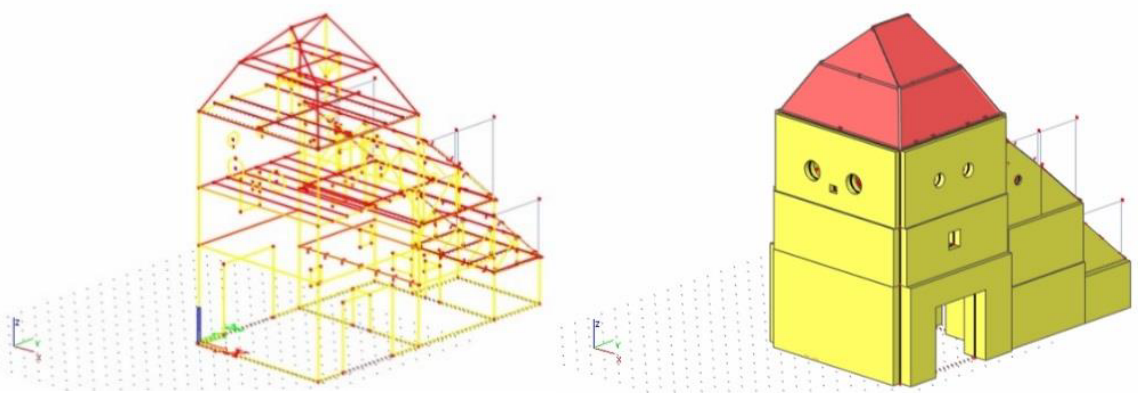

Fig. 3. The computational model of historical building - Upper Gate, framed and general.

In the calculation of own shapes we considered 4613 of 2D elements, 976 of 1D elements, and 5169 of network nodes. The calculation required assembling of 31,014 equations. For the mass group combination CM1 we used 10 natural frequencies. Amount of materials for x-direction is $411,678.05 \mathrm{~kg}$, the $\mathrm{y}$-direction is $411,678.05 \mathrm{~kg}$ and the $\mathrm{z}$ - 
direction is $411,682.24 \mathrm{~kg}$. The calculation was carried out on the basis of Lanczos and Mindlin bending theory.

Table 1. FE model - Example of the natural frequencies results.

\begin{tabular}{|c|c|c|}
\hline Natural mode no. & $\begin{array}{c}\text { Natural frequency } \\
{[\mathbf{H z}]}\end{array}$ & Vibration type \\
\hline 3 & 6.46 & asymmetrical \\
\hline 4 & 7.11 & asymmetrical \\
\hline 5 & 8.48 & asymmetrical \\
\hline 6 & 10.76 & symmetrical \\
\hline 7 & 12.09 & asymmetrical \\
\hline
\end{tabular}

\section{Experimental analysis of si in frequency domain}

Dynamic response of real tangible environment (half-space structure) by random excitation was measured by 2 lines of accelerometers with a frequency range of $1 \div 4000$ Hz. (Brüel-Kjaer), placed in terrain and roof of the object Fig. 4 Accelerometers measure the response in the vertical direction. Dynamic response in the observed points were measured in the form of vibration velocities $(\mathrm{m} / \mathrm{s})$, in three orthogonal directions $\mathrm{x}, \mathrm{y}, \mathrm{z}$. The measurement was performed using the "off - line". The, recorded signals are simultaneously stored on storage media PC/DX4 (program DISYS) and PCs AMILO - PC FS (NI CompactDAQ program). Evaluation of the measured data was carried out in laboratory conditions KSM - FCE - ZU based on the evaluation of software lines KSM (VL - KSM).

The measuring unit consisted of:

- $\quad$ piezoelectric accelerometers BK 8306 (Bruel - Kjaer) - 5pcs

- $\quad$ integration amplifier BK-2693-014 (Brüel-Kjaer), measuring PC/DX4 Notebook PC and FS File Format: MS Word

- $\quad$ NI cDAQ ${ }^{\mathrm{TM}}$-9191NI CompactDAQ One-Slot Wireless Chassis, Moxa AWK3121 With NI CompactDAQ
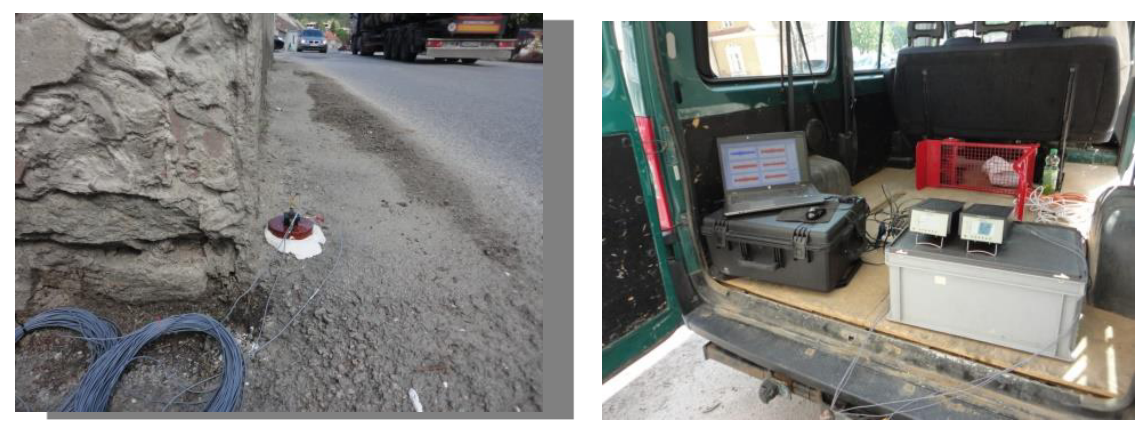

Fig. 4. The accelerometers positions in-situ experiment - B1.

Mechanical movement in the respective measuring point has been transformed by means of accelerometers and an electrical signal after amplification and integration from 
the acceleration signal $-a(t)$ to vibration velocity $-v(t)$, and it was conducted by means of Wi-Fi devices to the measuring central of the Department of Structural Mechanics (KSM) ZU University (ZU). These signals were recorded on laptops and PCs FS. Laptops are working in conjunction with the software NI Compact DAQ. The analog signal was recorded by parallel system DISYS and NI Compact DAQ, while the sampled frequency was $f_{s}=500 \mathrm{~Hz}$, with respect to the required criteria for sampling signals $\left(\Delta t<1 / 2 f_{\max }\right)$.

Table 2. Experimental and theoretical natural frequencies comparison.

\begin{tabular}{|c|c|c|c|c|}
\hline \multirow{2}{*}{$\begin{array}{c}\text { FEM } \\
\text { Natural } \\
\text { Frequency } \\
(\mathbf{H z})\end{array}$} & \multirow{2}{*}{$\begin{array}{l}\text { Calculated } \\
\text { Natural } \\
\text { Frequency } \\
\text { T815 (Hz) }\end{array}$} & $\begin{array}{c}\text { Experimental identified } \\
\text { frequency PSD }(\mathrm{Hz})\end{array}$ & \multirow[t]{2}{*}{$\begin{array}{c}\text { Exper. } \\
\text { CPSD }(\mathbf{H z})\end{array}$} & \multirow{2}{*}{$\begin{array}{c}\text { Exper. } \\
\text { GF } \\
(\mathbf{H z})\end{array}$} \\
\hline & & B1 & & \\
\hline & 1.13 & & & \\
\hline & 1.45 & & & \\
\hline \multicolumn{5}{|l|}{4.34} \\
\hline \multicolumn{5}{|l|}{5.3} \\
\hline 6.46 & & $6.3 ; 6.5 ; 6.7$ & $\begin{array}{c}6.1 ; 6.2 ; 6.3 ; \\
6.5 ;\end{array}$ & \\
\hline 7.11 & & $7.7 ; 7.8$ & $7.6 ; 7.8$ & \\
\hline 8.48 & 8.89 & $8.6 ; 8.7 ; 8.8$ & $8 ; 8.1 ; 8.7 ;$ & $8.6 ; 8.7$ \\
\hline 10.76 & 10.91 & $10.2 ; 10.7 ; 11.0 ; 11.4$ & $\begin{array}{c}9.9 ; 10.1 \\
10.6 ; 10.7 \\
11.3\end{array}$ & $\begin{array}{l}10.0 \\
10.1 ; \\
10.4 ; \\
10.8 ; \\
11.1 ; \\
11.4 ;\end{array}$ \\
\hline 12.09 & 11.71 & $11.7 ; 11.8 ; 12.2$ & $\begin{array}{c}11.5 ; 11.7 ; \\
11.8 ;\end{array}$ & $\begin{array}{l}11.7 \\
11.9 ;\end{array}$ \\
\hline 13.92 & & $14.0 ; 14.1 ; 14.2$ & 14.2 & $\begin{array}{l}13.9 ; \\
14.0 ; \\
14.1 ; \\
14.2 ; \\
14.5 ;\end{array}$ \\
\hline 15.52 & & 15.5; & 15.5 & $\begin{array}{l}15.4 ; \\
15.6\end{array}$ \\
\hline
\end{tabular}

As an example Figure 5. shows the results from signal spectral and amplitude analysis. Frequency peak finding are showed too. Identification of calculated FEM natural frequencies in experimental spectral analysis results are summarised in Table 2. In this table was summarised peak detection for the PSD (power spectral density), CPSD (cross power spectral density) and GF (gain factor) functions. The records of TATRA 815 lorry passing were used for this spectral analysis. 

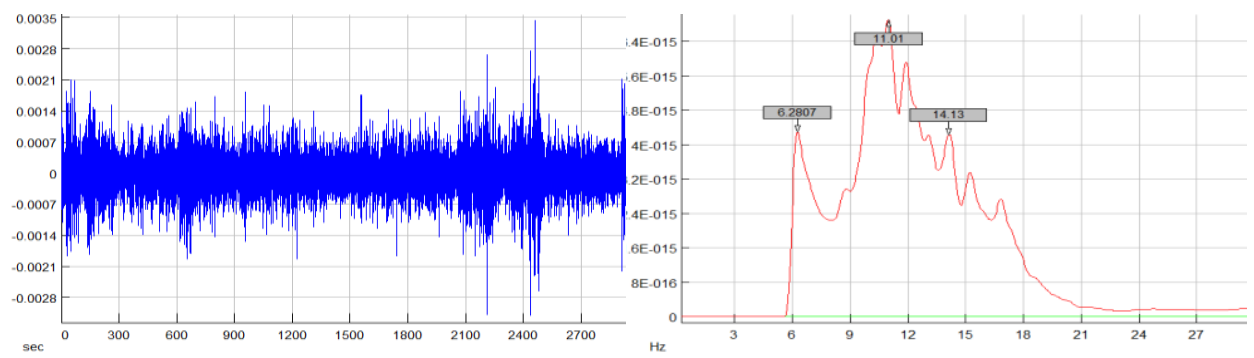

$\mathrm{v}_{1}(\mathrm{t}) ; \mathrm{B} 1_{\mathrm{z}}$

PSD G11 (f); B1

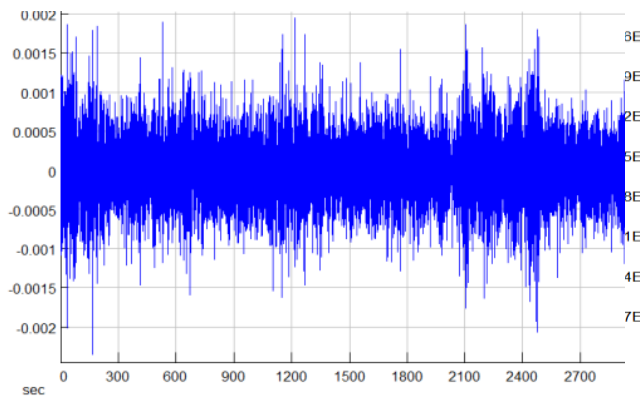

$\mathrm{v}_{1}(\mathrm{t}) ; B 1_{\mathrm{z}}$

PSD G11 (f); B1
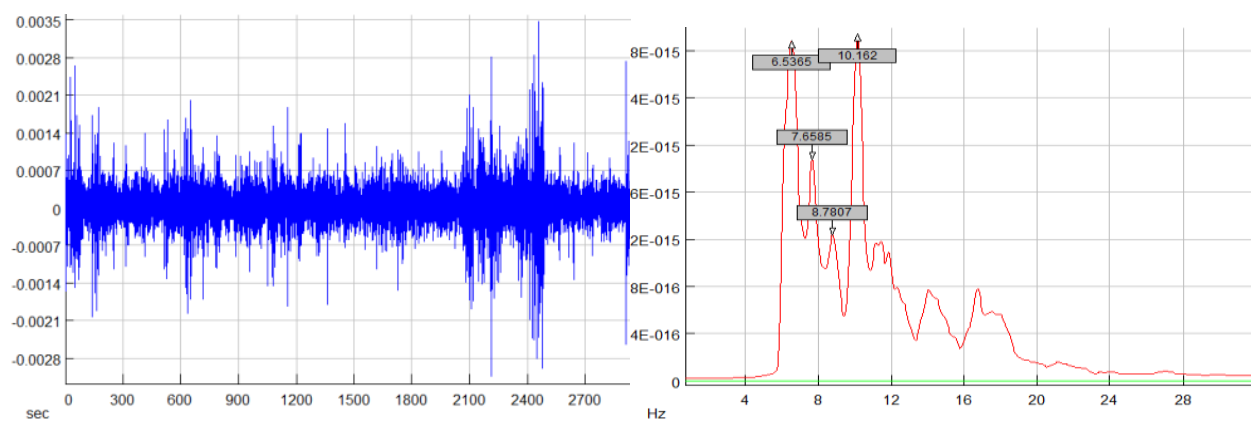

$\mathrm{v}_{1}(\mathrm{t}) ; \mathrm{B}_{\mathrm{z}}$

PSD G11 (f); B1 ${ }_{z}$
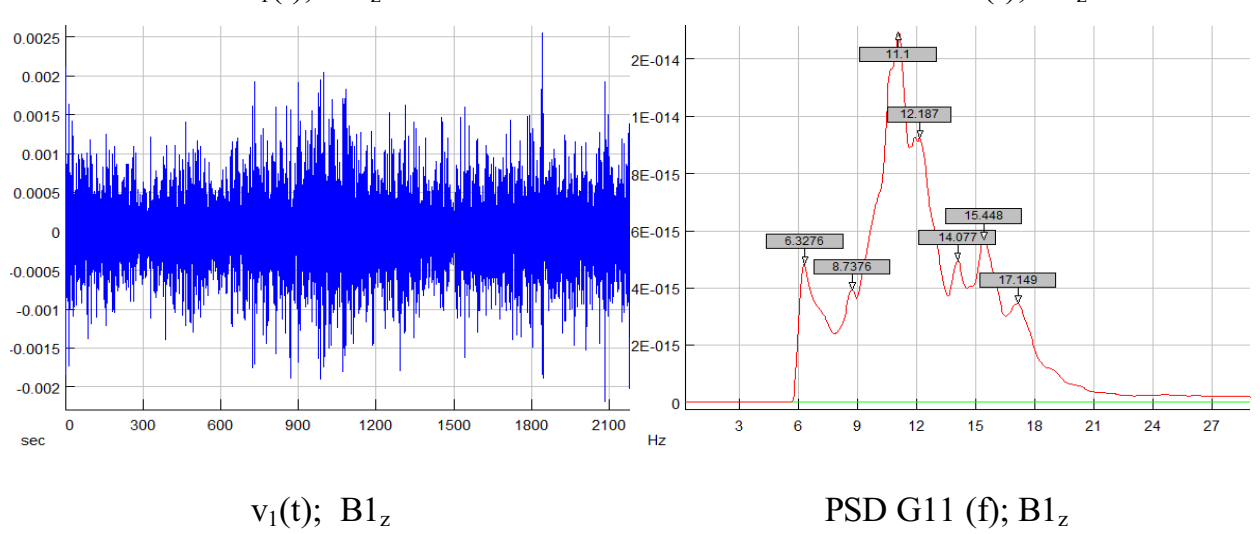

Fig. 5. The spectral analysis example. 


\section{Conclusions}

These case study contain the SI dynamic response frequency domain identification in three area. The first area of interest was numerical model of representative vehicle TATRA 815 natural frequencies identification. The second area of interest was the natural frequencies identification of the one important heritage building in south Slovakia. This building is traffic seismicity attacked intensively. The third and the most important area of this analysis was the experimental measurement evaluation. The experimental frequency detection was realised via spectral analysis. The main spectral functions was used for the peak detection. In SI area are expected the natural frequencies of vehicle and building. The important frequency band is between $4-30 \mathrm{~Hz}$. The identified natural frequencies of both numerical models are in highlighted frequency band $8-13 \mathrm{~Hz}$. Lower and upper frequencies are dumped. These experimental results verified numerical models results. The combination of numerical and experimental approach can be used for the traffic seismicity effect prediction. This prediction is significant for road reconstruction planning and monument restoration $[5,6,7,8]$.

\section{References}

1. K. Kantek, Modra mesto plné histórie - Sprievodca dejinami a pamiatkami (Modra, 1997)

2. L. Daniel, V. Valašková, J. Kortiš, Stav. a env. Inž. 10(2), 108-112 (2014)

3. I. Martinická, In: Poz. Komun. a dráhy. 6(1-2), 41-50 (2010)

4. V. Valašková, D. Papán, J. Fričová, Proc. Earth and Plan. Sc. 15, 193-198 (2015)

5. M. Marschalko, I. Yilmaz, K. Kubačka, T. Bouchal, M. Bednárik, M. Drusa, M. Bendová, Utilization of ground subsidence caused by underground mining to produce a map of possible land-use areas for urban planning purposes (Arab J Geosc, 2009)

6. M. Decký, M. Drusa, L. Pepucha, K. Zgútová, Earth Structures of Transport Constructions: Essex CM20 2JE, Pearson Education Limited (Edinburg Gate, Harlow, 2013)

7. J. Melcer, App. Mech. and Mat. 617, 29-33 (2014)

8. J. Melcer, D. Kuchárová, Frekvenčné charakteristiky nákladného vozidla. New trends in statics and dynamics of buildings : conference proceedings (Slovak University of Technology, Bratislava, 2013) 